\title{
Temporal and spatial patterns of urban sprawl and their implications on environmental planning in Mbarara Municipality
}

\author{
Bwanika Brian ${ }^{1}$ \\ Received: 30 September 2015 / Accepted: 1 August 2016/Published online: 11 August 2016 \\ (C) The Author(s) 2016. This article is published with open access at Springerlink.com
}

\begin{abstract}
The study was aimed at assessing the dynamics of land conversions for urban development and their impact on environmental planning in addition to assessing the characteristics of urban sprawl in Mbarara Municipality. To determine the dynamics of land conversion for urban development in Mbarara Municipality since 1984, Landsat images for the years 1984, 1999, and 2014 were classified using multispectral classification techniques to enable the creation of land cover maps. Population and built-up area density were used as a measure of sprawl for Mbarara Municipality. The built-up area had increased by $107 \%$ between 1984 and 1999 and by $37 \%$ between 1999 and 2014 while the overall growth of built-up area between 1984 and 2014 was found out to be $182 \%$. This variation in growth is attributed to the introduction of environmental controls and policies that largely checked the rate of growth between 1999 and 2014. The overall growth has affected the size of the area covered by other land uses which were seen to greatly fluctuate over the years. The characteristics of urban sprawl in Mbarara Municipality typically depict strip, cluster, and leapfrog sprawl. Based on the Organization for Economic Cooperation and Development (OECD) sprawl index, Mbarara Municipality was found to have sprawled at a rate of $7.7 \%$ between 1984 and 1999 and $-7.6 \%$ between 1999 and 2014. The overall sprawl rate between 1984 and 2014 was $-4.3 \%$. The study suggests that smart growth strategies, upholding zoning practices and the enactment of laws to check illegal land conversions are important to check sprawl.
\end{abstract}

Bwanika Brian

bwanikabrian@yahoo.com

1 Makerere University, Kampala, Uganda
Keywords Moran's $I$ - Sprawl $\cdot$ Sprawl index $\cdot$ Built-up density $\cdot$ Remote sensing $\cdot$ Average nearest neighbor

\section{Introduction}

The concept of urban sprawl is usually associated with the uncontrolled expansion of urban areas into the surrounding countryside, forming low-density and poorly planned patterns of development. As a product of the industrial revolution, it dates back to the nineteenth century when an expanding middle class in America started moving activities away from centers of growth due to pollution and overcrowding (Bruegmann 2005). In its path, urban sprawl involves the loss of rural land at the periphery of a city and consumes immeasurable acres of forests, farmland, woodlands, and wetlands (Pathan et al. 1991). As cities expand rapidly, the rural-urban fringe becomes a zone of interaction where urban and rural forces meet resulting into competition for land and other natural resources between newcomers and old communities (Beesley 1993). Urban sprawl is closely linked with the concept of per capita land consumption explained as a measure of how thinly or thickly a population is spread across a given area of land and this in turn determines its population density (Beck et al. 2003). The increasing population is a great contributing factor towards urban sprawl. This involves the conversion of open space or rural land into built-up, developed, or urbanized land over time. Other scholars argue that urban sprawl is development that is basically chopped-up, spread-out, segregated, low-density and is characterized by automobile dependent development (Rowley 2001). This situation is also known as horizontal spreading or dispersed urbanization and is associated with a scattered population of low density living in separate residential areas, with poor access, often over-dependent on motorized transport and missing well- 
defined centers of commercial activity (UNICEF 2012). In Africa, urban sprawl gradually manifested itself during the colonial era when towns or centers of growth were clearly marked along racial and occupational lines with the Europeans occupying suburban neighborhoods in contrast to the African zones that were located in peripheral and segregated neighborhoods (Kaplan et al. 2004). The gradual withdrawal of this era saw a tremendous rise of urban centers due to increasing population of Africans moving towards these already established centers of growth. Today, urban sprawl continues to be a big challenge to urban development because of its great impact on the environment. This study attempts to assess the temporal and spatial patterns of urban sprawl and their implications on environmental planning in Mbarara Municipality.

\section{Data and methods}

\section{Study area}

Mbarara Municipality is located about $266 \mathrm{~km}$ from Kampala city on Kampala-Kabale highway. It is one of the 22 municipalities that exist in the current urban administrative structure of Uganda. It is composed of three main administrative divisions with an estimated population of over 85,000 people (Ssengendo 2013). These divisions are Kamukuzi, Kakoba, and Nyamitanga (Figs. 1 and 2). Each of these has two wards: Kamukuzi division with Kamukuzi and Ruharo wards, Kakoba division with Kakoba and Nyamityobora wards, and Nyamitanga division with Katete and Ruti wards (Kabenge and Mfutumkiza 2013). These three divisions occupy a total area size of about 5147 ha. Nyamitanga division shares the biggest portion in terms of geographical extent covering 2229 ha, followed by Kamukuzi covering 1610 ha and Kakoba covering 1308 ha (UN Habitat 2012). Attempts are being made by the municipal council to be elevated to city status and if successful, this would result into the incorporation of the current sub counties of Kashari and Rwampara (Muneza 2014). The municipality generally lies at an average altitude of $1432 \mathrm{~m}$ above sea level and is characterized by hilly areas separated by short, small, and shallow valleys. Due to the nature of its climatic elements such as average precipitation and temperature of $1125 \mathrm{~mm}$ per year and $25^{\circ} \mathrm{C}$, respectively, vegetation is mainly open savannah grass which is, in some places mixed with woodland (UN Habitat 2012). Figures 1 and 2 show the location of Mbarara Municipality.

\section{Determining the dynamics of land conversions for urban development}

Landsat satellite imagery scenes corresponding to Path 172 , Row 060 encompassing Mbarara Municipality for the years
1984, 1999, and 2014 were obtained from the US Geological Survey website (www.usgs.glovis.gov). The period between 1984 and 2014 was selected as it was largely characterized by a conducive political atmosphere and was thus assumed to have encouraged steady urban growth in Mbarara Municipality as compared to the previous years. The year 1999 was selected as it was a good basis for the assessment of urban development in Mbarara Municipality between 1984 and 2014. Landsat images were used as they are of highquality and with multi-spectral content of the surface of the Earth. The characteristics of these images are presented in Table 1.

Using the Arc GIS 9.3 software, the image for 1984 was resampled to a $30-\mathrm{m}$ resolution to ensure uniformity with the images of 1999 and 2014 each obtained at a 30-m resolution. This was done to reduce the geometric discrepancies as Landsat multi-spectral scanner images namely Landsat $1-3$ and Landsat $4-5$ have a resolution of $60 \mathrm{~m}$ (Baboo and Devi 2010). False color composites of these images were created by combining bands 5,4,3 for the image of 2014, bands 4,3,2 were used for the image of 1999 and 1,2,4 for the 1984 image (Fig. 3) (http://landsat.usgs.gov/L8_band_combos.php). The color composites for each image were then over laid with the Mbarara Municipality shape file. The study area was derived from each of the three images for each of the three years namely 1984, 1999, and 2014.

Classification was done for each color composite in which six clusters were chosen and then classified by maximum likelihood. The assignment of classes was done by choosing different colors to represent the given land cover types. This was guided by a 2012 high-resolution panchromatic ASTER image as well as Google Earth historical imagery. Basing on the classes provided in the 2001 Uganda land cover map produced by the National Biomass study, six classes were derived to represent major land cover types in Mbarara Municipality (Fig. 4). These included the following:

1. Built-up, which was used to represent commercial and residential housing structures as well as tarmacked roads.

2. Forest represented trees in large numbers or a collection of trees.

3. Swamp was used to represent papyrus vegetation and swamps and wetlands.

4. Grassland was used to represent green belts or spaces and bushes.

5. Bare land was used to portray areas covered by sand or soil.

6. Cropland represented land under cultivation.

A total of 60 random points in the study area were established and visited using a GPS receiver as part of ground truthing to ascertain their classification classes. Classes generated for the classified images of 1999 and 1984 were 
Fig. 1 Mbarara Municipality Base map

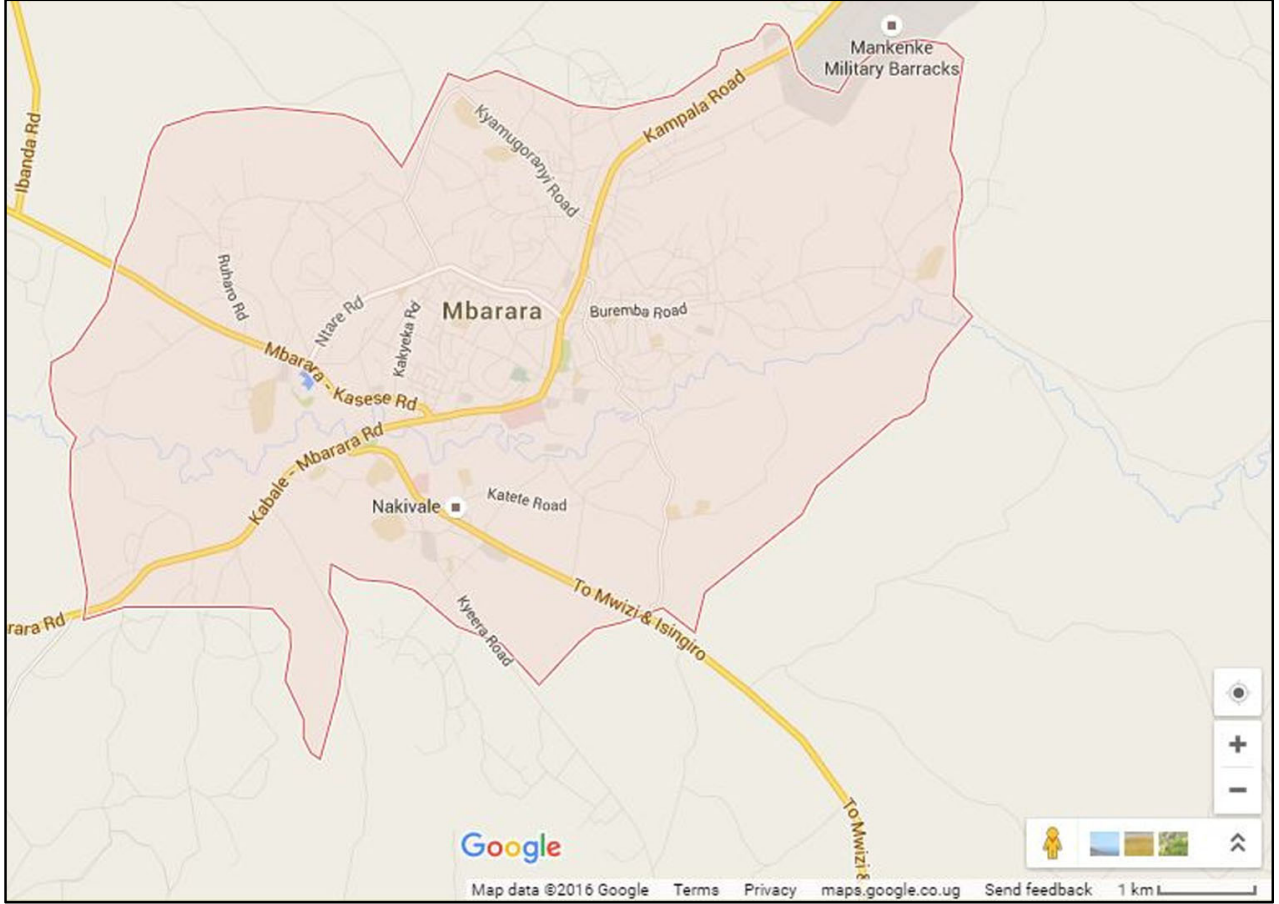

ascertained with reference to Google Earth historical imagery and then classification error matrices developed to assess the accuracy of classification using 60 random points. In conformance with standard accuracy assessment techniques, an error matrix was produced and used to compute user's accuracy, producer's accuracy, and overall accuracy for the 2014 image classification. In addition, for each classification, kappa statistic $(K)$ as given by Eq. 1 was computed to determine the significance of the accordance between each of the classifications (Table 3) (Campbell 2007).

$K=\frac{\text { Observed-Expected }}{1-\text { Expected }}$

Where:

Observed $=$ Overall value for percent correct and

Expected $=$ Estimate of the contribution of chance agreement to the observed percent correct.

The reliability of each of the computed kappa statistic was determined by use of a $Z$ score in Eq. 2 based on kappa variance using equation given by Congalton and Green (1999).

$Z=\frac{K}{\sqrt{ } \operatorname{var}(K)}$

Where:

$K=$ kappa statistic

The total number of pixels occupied by each class was converted to hectares for easy interpretation. Given that the Landsat images obtained were at a resolution of $30 \mathrm{~m}$, each pixel was taken to represent an area of $900 \mathrm{~m}^{2}$ (Shermeyer and Haack
2015). This was multiplied by the total number of pixels covered by the entire municipality for each year and the product converted to hectares. This was done for each year for all the classes. The percentage coverage of each class was also calculated.

Slight variations in the total number of pixels of Mbarara Municipality for each year came about as a result of differences in characteristics of sensors used to obtain each of the images over the given period (Paolini et al. 2006).

The dynamics of land conversions for urban development for 1984 to 1999 and 1999 to 2014 were detected by the use of raster-based relational operational tools. The actual area of new built-up areas was calculated by converting the area covered by pixels to hectares. These new output maps were overlaid with the 1984 and 1999 land cover maps so as to make it possible to identify the different types of affected pre-existing land cover. They were then combined with the raster maps for the 1999 and 2014 land cover respectively to determine the extent to which each land cover was affected.

\section{Characterizing urban sprawl}

In order to assess the characteristics of sprawl, data was collected on built-up area, population, and settlement patterns for the respective divisions in Mbarara Municipality. A thorough review of documents related to urban growth, population, and settlement for Mbarara Municipality was done. Other sources of data included the local authorities, such as Mbarara Municipal Council, as well as the Mbarara Local Government offices. Geographical information system 
Fig. 2 Study area

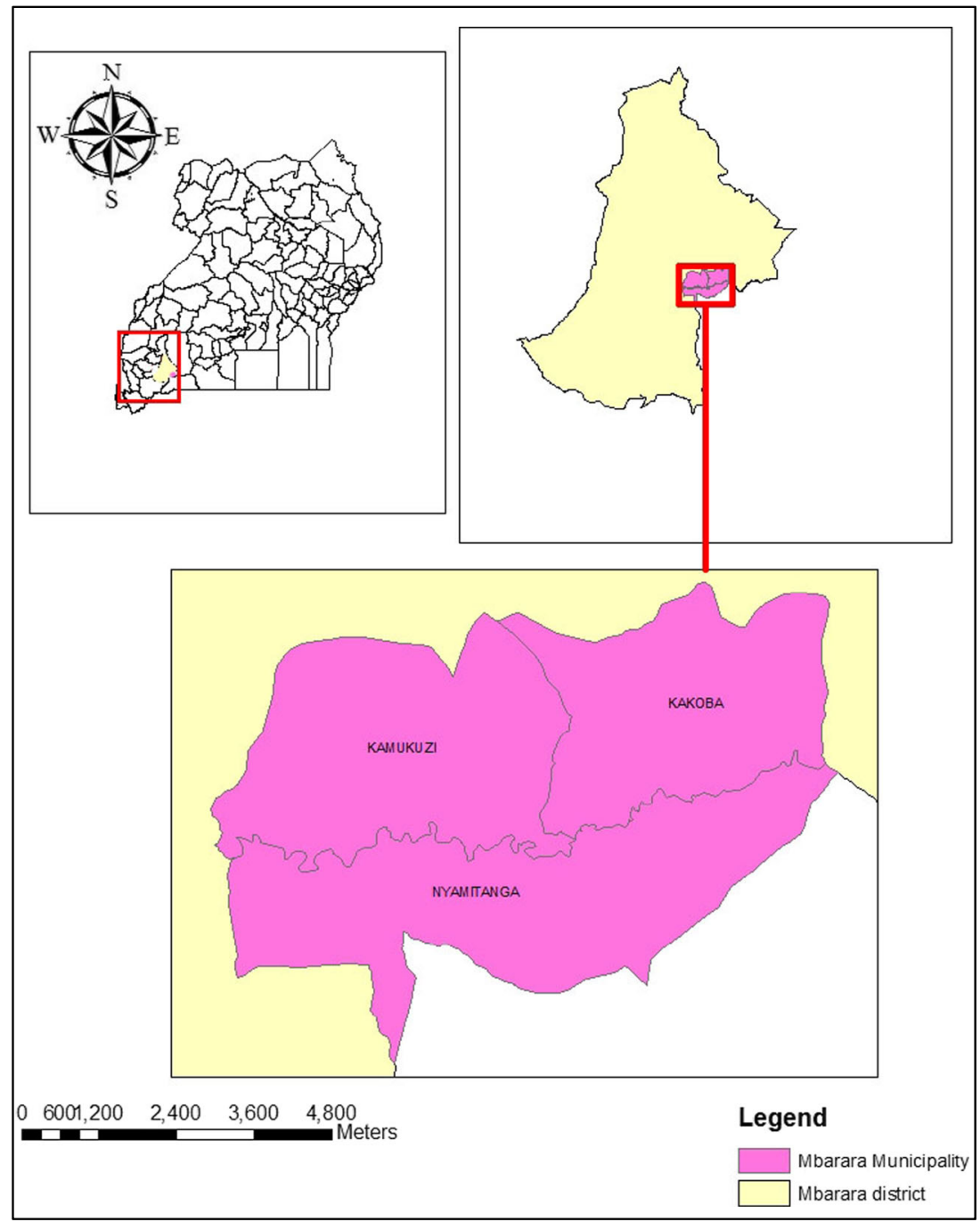

techniques were used to analyze and study the direction of sprawl in Mbarara Municipality since 1984. Layers of Mbarara Municipality built-up area for the years 1984, 1999, and 2014 were integrated with the Mbarara Municipality shape file to enable the study of the spatial and temporal patterns of sprawl. A layer of both major and secondary roads in Mbarara Municipality was also used to study the interaction of built-up areas along the road network. In accordance with literature on sprawl, attempts were made to estimate a sprawl index. The OECD (Organization for Economic Cooperation and Development) sprawl index was used to statistically assess the compactness and interaction of the built-up area in Mbarara Municipality with its population. The OECD equation was used as it was found most suitable for calculating the increase in the area of urbanized land over time relative to changes in population as well as change in the gross density of the urbanized area (Burchfield et al. 2006). Moreover, this equation is in accordance to Ewing et al. 2002, Fulton et al. 2001, Galster et al. 2001, as it is important in determining how efficiently land is being used is to determine whether the rate of growth of the urban area exceeds the rate of growth in population or dwelling units. Some researchers use this
Table 1 Characteristics of Landsat images

\begin{tabular}{lllll}
\hline Sensor & Resolution & Projection & Date acquired & Cloud cover \\
\hline Landsat 4-5 MSS & $60 \mathrm{~m}$ & UTM WGS_1984 & $21 / 02 / 1984$ & Less than 10\% \\
Landsat 7 & $30 \mathrm{~m}$ & UTM WGS_1984 & $31 / 12 / 1999$ & Less than 10\% \\
Landsat 8 OLI & $30 \mathrm{~m}$ & UTM WGS_1984 & $07 / 02 / 2014$ & Less than 10\% \\
\hline
\end{tabular}



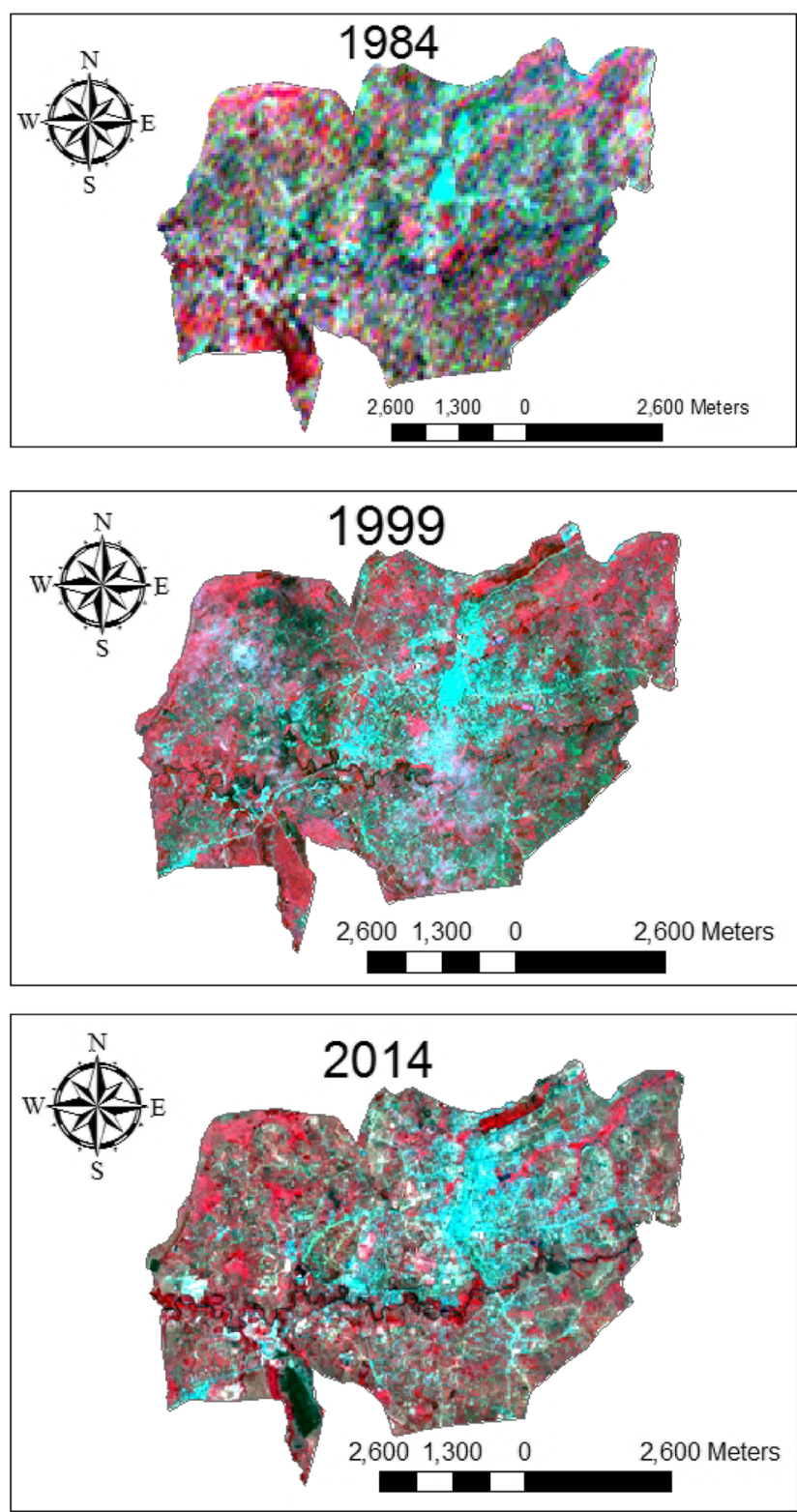

Fig. 3 False color composites

measure to establish whether a region is "sprawling" or not. The OECD sprawl index according to Brezzi and Veneri (2014) is given by Eq. 3 below:

$\mathrm{SI}_{\mathrm{i}}=\frac{\left[\operatorname{urb}_{\mathrm{i}, \mathrm{t}+\mathrm{n}}-\left(\operatorname{urb}_{\mathrm{i}, \mathrm{t}} *\left(\frac{\text { pop }_{\mathrm{i}, \mathrm{t}+\mathrm{n}}}{\text { pop }_{\mathrm{i}, \mathrm{t}}}\right)\right)\right]}{\mathrm{urb}_{\mathrm{i}, \mathrm{t}}} * 100$

Where:

$i=$ Mbarara Municipality

$t=$ initial year,

$t+n=$ final year,

urb $=$ built-up area in square kilometers

pop $=$ total population of the area.
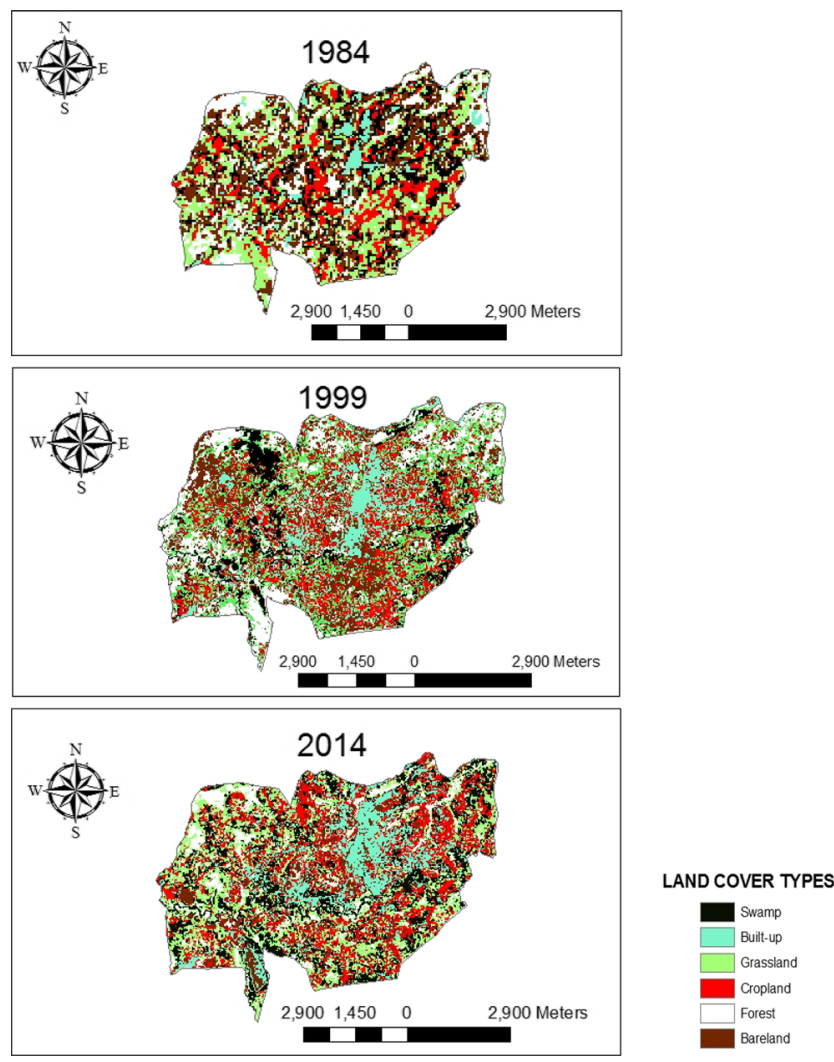

Fig. 4 Classified land cover maps

The urbanized land was computed as land covered by private and commercial buildings, infrastructure, and major transportation infrastructure.

The result from the OECD sprawl index is interpreted in three ways:

1. It is equal to zero when both population and built-up area are stable over time.

2. It is bigger than zero when the growth of built-up area is greater than the growth of population; thus, the density of the metropolitan area has decreased. This means that the area is experiencing sprawl.

3. It is lower than zero when the growth of built-up area is smaller than the growth of population; thus, the density of the built-up area has increased. This means that the area is not experiencing urban sprawl.

The rate of growth of the built-up area of Mbarara Municipality between 1984 and 1999 and 1999 and 2014 was used to determine the trend and type of growth that had been experienced during this period.

The direction of growth in Mbarara Municipality was determined using spatial statistics where a point layer generated from the combination of layers of built-up areas for the years 1984, 1999, and 2014. The standard deviation ellipse was derived for the combined built-up areas from 1984 to 2014 . 
If the features are normally distributed, the ellipse covers approximately $68 \%$ of them in the pattern (O'Sullivan and Unwin 2003). The value in the rotation field represented the rotation of the long axis measured clockwise from noon.

The characterization of linear patterns of sprawl was done by the creation of buffers measuring $100 \mathrm{~m}$ along transport routes.

A scatter plot graph was generated to illustrate the built-up density patterns from the main municipality center using values from the combined built-up raster map of years 1984 , 1999, and 2014 basing on methods attributed to Murayama (2011). The understanding of spatial patterns of built-up density was essential for the discovery of sprawling tendencies in Mbarara Municipality with reference to distance from the main municipality center. According to Knaap et al. (2005), the distance to the central business district or main center is among the measures of sprawl under accessibility.

Further investigation on sprawl was done with the aid of a built-up density map for Mbarara Municipality encompassing the years 1984, 1999, and 2014. The kernel density was calculated using a search radius of $500 \mathrm{~m}^{2}$ and a cell size of 30 . The classes of the density map were then classified into three categories: "high, medium, and low" as follows (Table 2). This was done in accordance to methods used by Zhou (2015) to delineate built-up areas.

The identification of both low-density development or cluster and leapfrog sprawl and the extent at which they were being experienced in Mbarara Municipality was done with the use of the use of spatial statistics tools particularly, "Moran's I" and "average nearest neighbor." The nearest neighbor index is expressed as the ratio of the observed distance divided by the expected distance. The expected distance is the average distance between neighbors in a hypothetical random distribution (Ojima and Hogan 2008).

If the index is less than 1 , the pattern exhibits clustering and if it is greater than 1 , the trend is towards dispersion. This was calculated using the average nearest neighbor function under the spatial statistics tools.

The average nearest neighbor uses distance relations while Moran's I measures spatial autocorrelation based on attributes, that is, the measure of how close objects are in comparison with other objects. In technical terms, Moran's $I$ is a measure of global spatial autocorrelation, an indication of whether similar values of a particular variable are closer together in space (Moran 1948).

Given a set of features and an associated attribute, Moran's $I$ evaluates whether the pattern in a specified region is

Table 2 Thresholds of built-up density

\begin{tabular}{lll}
\hline Low & Medium & High \\
\hline $0-22,237$ & $22,238-44,473$ & $44,474-66,709$ \\
\hline
\end{tabular}

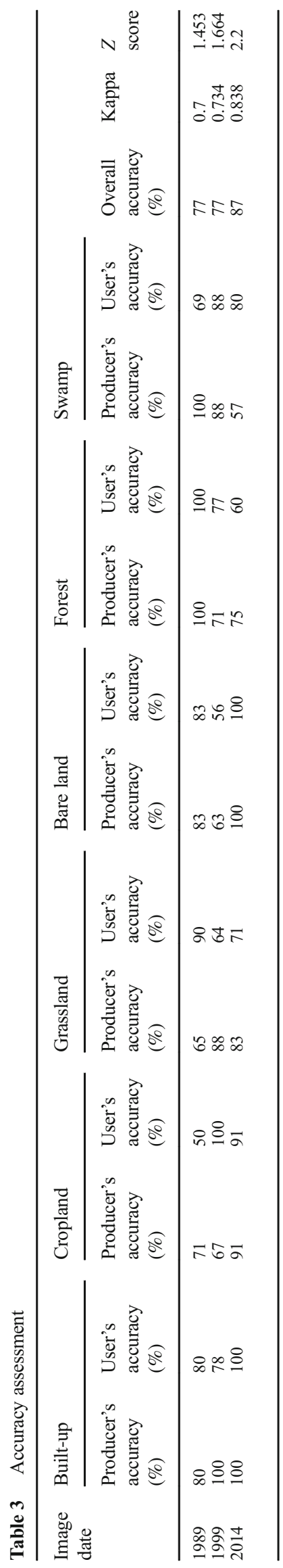


Table 4 Land conversions for urban development in Mbarara Municipality for the years 1984, 1999, and 2014

\begin{tabular}{|c|c|c|c|c|c|c|c|c|c|}
\hline & Built-up & Forest & Swamp & Bare land & Cropland & Grassland & Total & & \\
\hline \multirow[t]{2}{*}{1984} & Hectares & & 229.23 & 696.15 & 788.22 & 981.45 & 643.23 & 1187.73 & 4526.1 \\
\hline & $\%$ & & 5.06 & 15.4 & 17.41 & 21.68 & 14.21 & 26.24 & 100 \\
\hline \multirow[t]{3}{*}{1999} & No. of pixels & & & & & & & & \\
\hline & Hectares & & 473.67 & 878.22 & 570.06 & 676.46 & 797.76 & 1095.39 & 4527.36 \\
\hline & $\%$ & & 10.46 & 19.4 & 12.59 & 14.3 & 17.62 & 24.19 & 100 \\
\hline \multirow[t]{3}{*}{2014} & No. of pixels & & & & & & & & \\
\hline & Hectares & & 648.45 & 454.32 & 1071 & 275.13 & 1001.61 & 1077.3 & 4527.81 \\
\hline & $\%$ & & 14.32 & 10.03 & 23.65 & 6.076 & 22.12 & 23.79 & 100 \\
\hline \multirow[t]{6}{*}{ Change } & 1984-1999 & $\mathrm{Ha}$ & 2715 & 9062 & -218.22 & -334.99 & 8220.77 & -92.34 & 1.26 \\
\hline & & $\%$ & 5.4 & 4 & -4.82 & -7.38 & 3.41 & -2.05 & \\
\hline & 1999-2014 & $\mathrm{Ha}$ & 174.78 & -423.9 & 500.94 & -401.33 & 203.85 & -18.09 & 0.45 \\
\hline & & $\%$ & 3.86 & -9.37 & 11.06 & -8.224 & 4.5 & -0.4 & \\
\hline & 1984-2014 & $\mathrm{Ha}$ & 419.22 & -241.8 & 282.78 & -706.32 & 358.38 & -110.43 & 1.71 \\
\hline & & $\%$ & 9.26 & -5.37 & 6.24 & -15.604 & 7.91 & -2.45 & \\
\hline \multirow[t]{2}{*}{ Change per annum } & 1984-2014 & $\mathrm{Ha}$ & 1.83 & -0.35 & 0.35 & -0.71 & 0.6 & -0.09 & \\
\hline & & $\%$ & 6.2 & -1.1 & 1.2 & -2.3 & 1.9 & -0.3 & \\
\hline
\end{tabular}

expressed as clustered, dispersed, or random. A value of close to -1 indicates an evenly distributed pattern, whereas a value closer to +1 indicates significant clustering. A value of 0 indicates a random spatial distribution (Burchfield et al. 2006).

Values from the Moran's I were calculated using spatial autocorrelation under the statistics tool in Arc GIS 9.2 with a distance band or threshold distance $500 \mathrm{~m}$. This distance was selected as a rough estimate of the minimum walkable distance between neighborhoods.

\section{Results}

Figures 3 and 4 show false color composites and land cover maps generated for Mbarara Municipality for the years 1984, 1999 , and 2014.

The producer's, user's, and overall accuracy values as well as the kappa and $Z$ scores were presented in Table 3.

The patterns of land cover change from 1984 to 1999 and 2014 and the overall land conversions for each cover type in Mbarara Municipality were calculated and presented in Table 4.

The built-up area of Mbarara Municipality has expanded since 1984 with the year 2014 experiencing the highest percentage of built-up areas. Its area coverage has risen from $5.06 \%$ in 1984 to $10.4 \%$ in 1999 and $14.3 \%$ in 2014. This puts the percentage growth rate of the built-up area of Mbarara municipality since 1984 at $6.2 \%$ per annum gaining 1.83 ha each year.

The status of forest cover in Mbarara Municipality since 1984 has seen fluctuations in its percentage coverage. In 1984,
Mbarara Municipality had total forest area coverage of $15.4 \%$. This percentage rose by 4 to $19.3 \%$ in 1999 . However, it dropped by $9.3 \%$ between 1999 and 2014 and currently, forests in Mbarara Municipality occupy just $10 \%$ of the total land cover and lose $1.1 \%$ equivalent to 0.4 ha per year.

The percentage cover of swamps in Mbarara Municipality has been fluctuating since 1984. Swamps occupied $17.4 \%$ of the total land cover in 1984. Their percentage cover dropped between 1984 and 1999 by 9.4 to $12.5 \%$ in 1999 . However, their coverage increased in the period between 1999 and 2014 and is currently at $23.6 \%$ and is growing at a rate of $1.2 \%$ per year.

The percentage cover of bare land in Mbarara Municipality has dropped since 1984 when it covered $21.6 \%$. This number reduced to $14.3 \%$ in 1999 and dropped further to $6 \%$ in 2014. Bare land has been losing an area equivalent to $2 \%$ per year since 1984.

Table 5 Land converted to built-up areas in Mbarara Municipality

\begin{tabular}{lllll}
\hline & $1984-1999$ & & $1999-2014$ & \\
\hline Land cover & Hectares & Percentage & Hectares & Percentage \\
Grassland & 330 & 36 & 83 & 10.9 \\
Swamp & 97 & 13 & 183 & 24.2 \\
Bare land & 200.07 & 24 & 202 & 26.71 \\
Cropland & 135.45 & 17 & 36 & 4.7 \\
Forest & 82.62 & 10 & 252.09 & 33.34 \\
Total & 844.56 & & 756.09 & \\
\hline
\end{tabular}


Fig. 5 Land affected by new built up areas by the year 1999

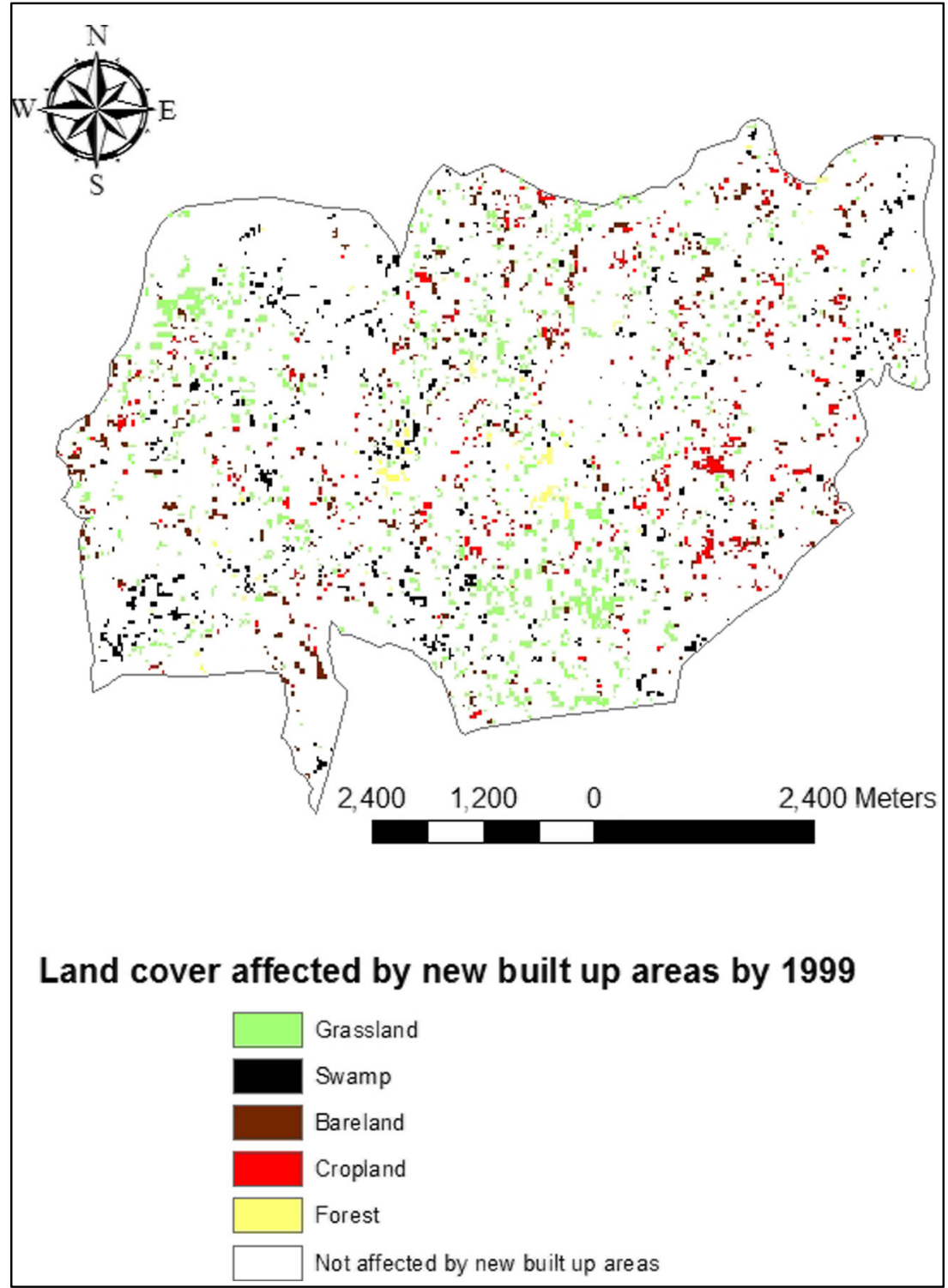

Cropland in Mbarara Municipality has risen since 1984 when it occupied $14.21 \%$ of the total land cover. It increased by 3.41 to $17.6 \%$ in 1999 and further increased to $22.1 \%$ in 2014. Cropland expanded at a rate of $1.9 \%$ or gained 0.6 ha between 1984 and 2014.

Grassland in Mbarara Municipality has continued to decrease over the years as it occupied up to $26.24 \%$ of the total land cover in Mbarara Municipality in 1984. However, this percentage dropped as grassland only comprised of $24.1 \%$ of the total land cover in 1999. It further dropped to $23.7 \%$ in 2014 putting the percentage loss of grassland in Mbarara Municipality at $0.3 \%$ from 1984 to 2014 .

Land covered by built-up areas has risen gradually from 229.3 ha in 1984 to 648.45 ha in 2014 . This rise has without doubt affected the area covered by other cover types over these years (Table 5). Figures 5 and 6 illustrate the extent to which land conversion for urban development particularly built-up area in Mbarara Municipality has replaced preexisting land cover of 1984 and 1999.

\section{Characteristics of sprawl patterns in Mbarara Municipality}

This section presents the characteristics of sprawl in Mbarara Municipality including its rate, its forms, and its major indicators. For this study, the urbanized area was considered to be land covered by both private and commercial buildings, social infrastructure such as hospitals and schools as well as tarmacked roads. Estimates of the population statistics for the three divisions were obtained from the Mbarara Municipal council planning unit and summed up to obtain the total population for 1984, 1999, and 2014. The sprawl 
Fig. 6 Land affected by new built-up areas by the year 2014

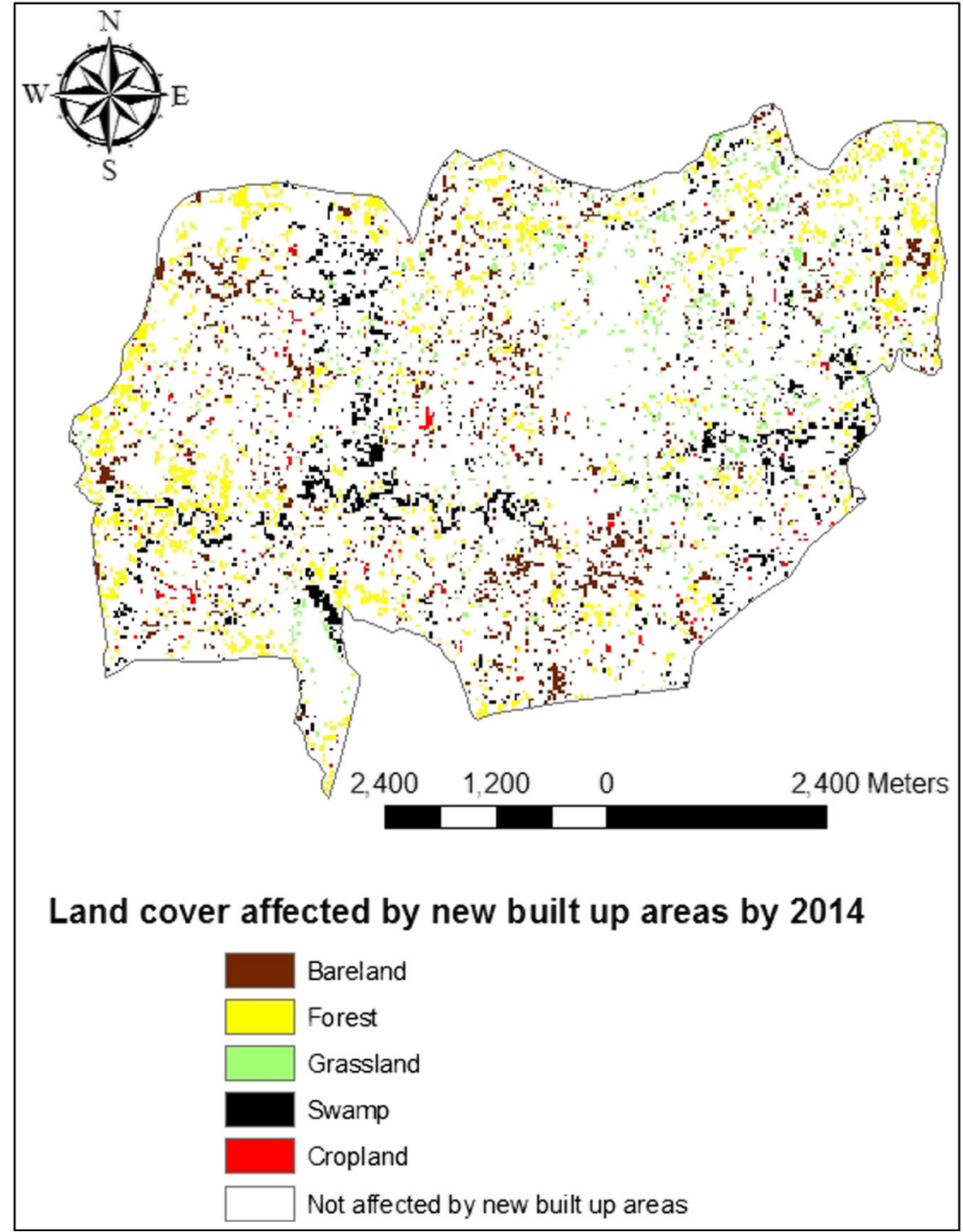

index was then used to calculate the sprawl rate between 1984 and 1999, 1999 and 2014 and the overall sprawl rate of Mbarara Municipality between 1984 and 2014 as well as the per capita land consumption (Table 6).

\section{Characteristics of sprawl}

The standard deviation ellipse created by the directional distribution tool was essential in showing the general location of the pattern and directional trend of urban growth in terms of built-up features for Mbarara Municipality (Fig. 7).

The ellipse generated for the built-up area of Mbarara Municipality as shown in Fig. 7 was oriented to the north east direction. This therefore shows that Mbarara Municipality has majorly been growing towards the north east direction namely Kakoba division since 1984.

More still, analysis of the built-up areas over the years revealed that the growth patterns of Mbarara Municipality tend to follow roads (Fig. 8) in many areas. The buffers created show
Table 6 Sprawl rate of Mbarara Municipality

\begin{tabular}{|c|c|c|c|c|c|c|c|}
\hline \multirow[t]{2}{*}{ Year } & \multirow[t]{2}{*}{ Hectares } & \multirow{2}{*}{$\begin{array}{l}\text { Square } \\
\text { kilometers }\end{array}$} & \multirow[t]{2}{*}{ Population } & \multirow{2}{*}{$\begin{array}{l}\text { Per capita land } \\
\text { consumption }(\mathrm{Ha})\end{array}$} & \multicolumn{3}{|c|}{ Sprawl rate $(\%)$} \\
\hline & & & & & 1984-1999 & 1999-2014 & 1984-2014 \\
\hline 1984 & 229.23 & 2.3 & 28,720 & 0.01 & & & \\
\hline 1999 & 473.67 & 5 & 60,235 & 0.01 & 7.6 & -7.7 & -4.3 \\
\hline 2014 & 648.45 & 7 & 89,000 & 0.01 & & & \\
\hline
\end{tabular}


Fig. 7 Direction of growth

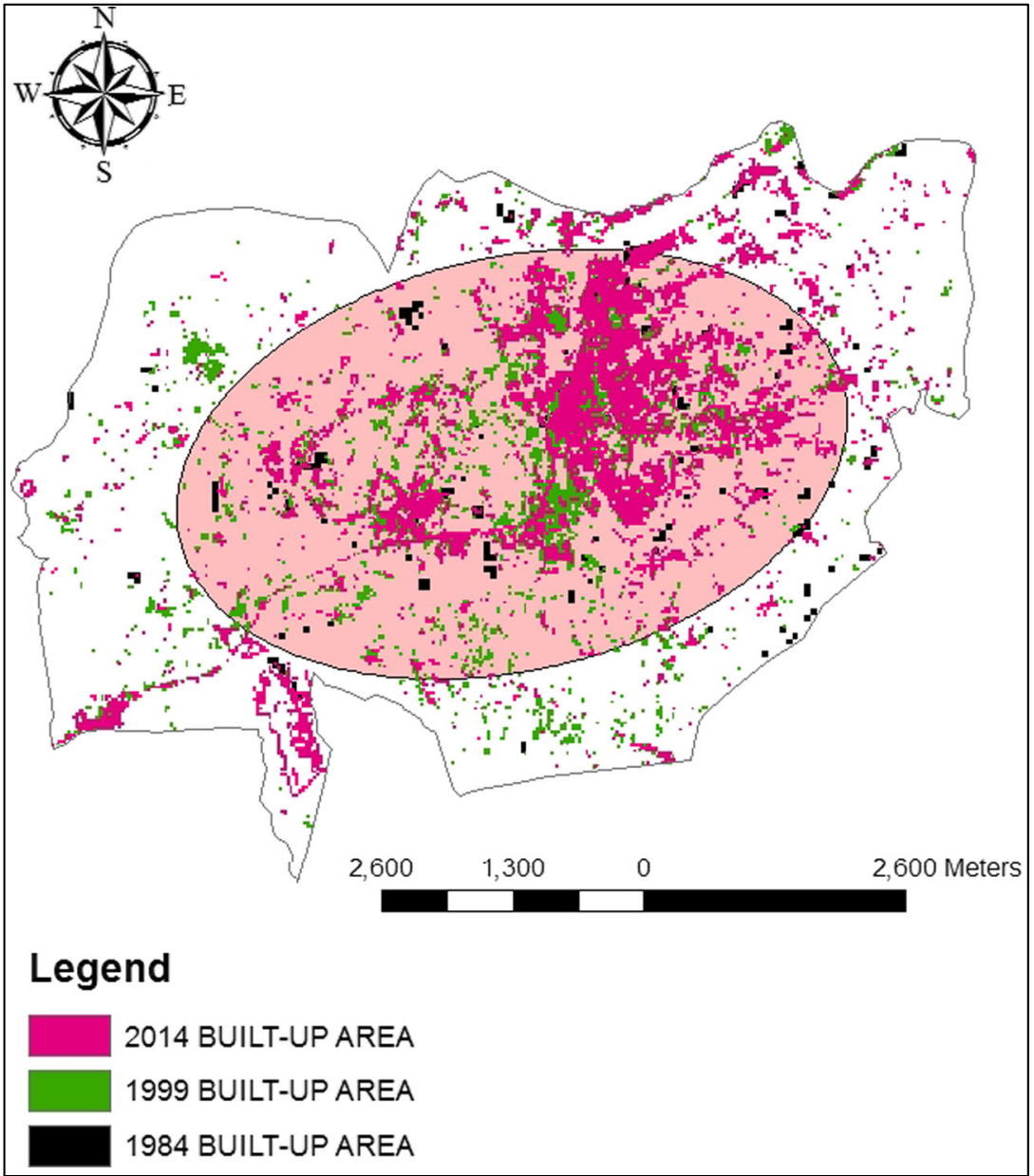

that developments since 1984 have continued to occur within $100 \mathrm{~m}$ of the road radius. This form of development is evidence that Mbarara Municipality is experiencing strip sprawl where development occurs on both sides of major roads.

Figure 9 shows the spatial distribution of built-up density of Mbarara Municipality since 1984 to 2014 in square kilometers as it appears across a distance of $6.45 \mathrm{~km}$. The size of the built-up area is seen to fall as the distance from the main center increases. This spatial pattern of built-up density is evidence of the sprawling nature of development in Mbarara Municipality.

The distribution of the density of built up areas in Mbarara Municipality is further illustrated in Fig. 10 using three thresholds: low, medium, and high.

High-density areas in Mbarara Municipality were found within 44,474 to $66,709 \mathrm{~m}^{2}$. Medium-density areas appeared within 22,238 and $44,473 \mathrm{~m}^{2}$ while the built-up areas of lowdensity occupied between $0-22,237 \mathrm{~m}^{2}$.

With visual analysis and interpretation of Figures 9 and 10 , it was revealed that there is not a single city center in Mbarara Municipality as it is polycentric given by the number of high-density areas as shown in both figures. It also revealed that the spatial pattern of built-up areas in the municipality was highly disconnected or disjointed in many parts. These findings were used as a basis to conclude that Mbarara Municipality was experiencing both leapfrog and cluster sprawl. Low- and medium-density areas were classified as areas experiencing leapfrog sprawl.

The nature of leapfrog development was revealed with the calculation of the average nearest neighbor under the spatial statistics tool in Arc GIS 9.2 in which the nearest neighbor ratio was 1.649138. This translates to a form of urban development that tends towards dispersion. Leapfrog development is basically of low density and on the periphery of existing urban areas. An example of this type of sprawl encircled below in Mbarara municipality was taken from Ruharo ward in Kamukuzi division (Fig. 11)

Given the number of high-density patches of built-up areas in Figs. 9 and 10 and the calculation of Moran's $I$ statistic found to be at 0.91 , it can be concluded that since this score is so close to +1 , it reveals a clustering nature of urban development in Mbarara Municipality. Cluster development or sprawl is associated with clustered areas that are mostly located long distances away from the main commercial areas. These are mostly well-planned residential areas which are of high density in themselves but located far away 
Fig. 8 Strip sprawl in Ruti ward, Nyamitanga division

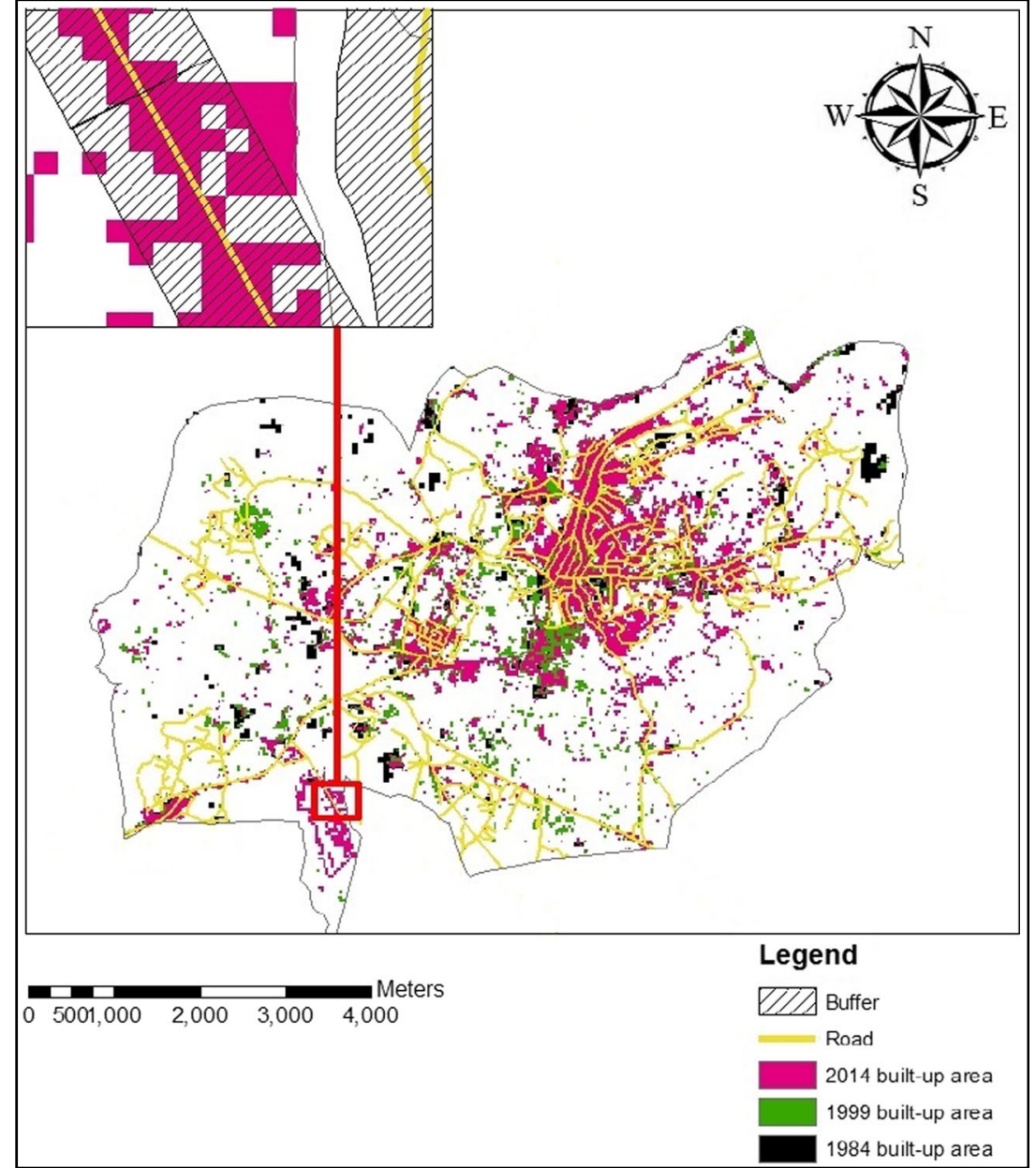

from the main central business areas (CBA). It is further understood as a scattered or discontinuous form of urbanization with disjointed and isolated patches of high-density urban growth.

An example of clustering encircled, in Mbarara Municipality, was obtained from Ruharo ward in Kamukuzi division as given in Fig. 12

\section{Discussion}

Land conversion refers to the changing of the status of land from one use to another. Land cover is influential in determining which land use types are suitable for a particular area. In Mbarara Municipality, different land cover types have been used for different land uses since 1984, and therefore, cover
Fig. 9 Distance from the main municipality center

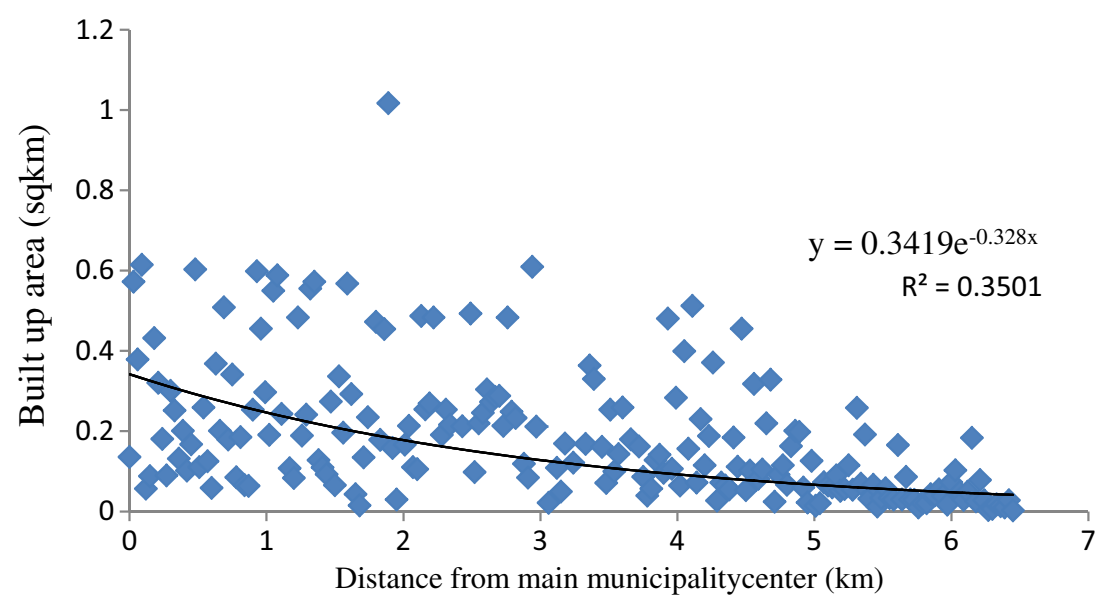


Fig. 10 Mbarara Municipality built-up density

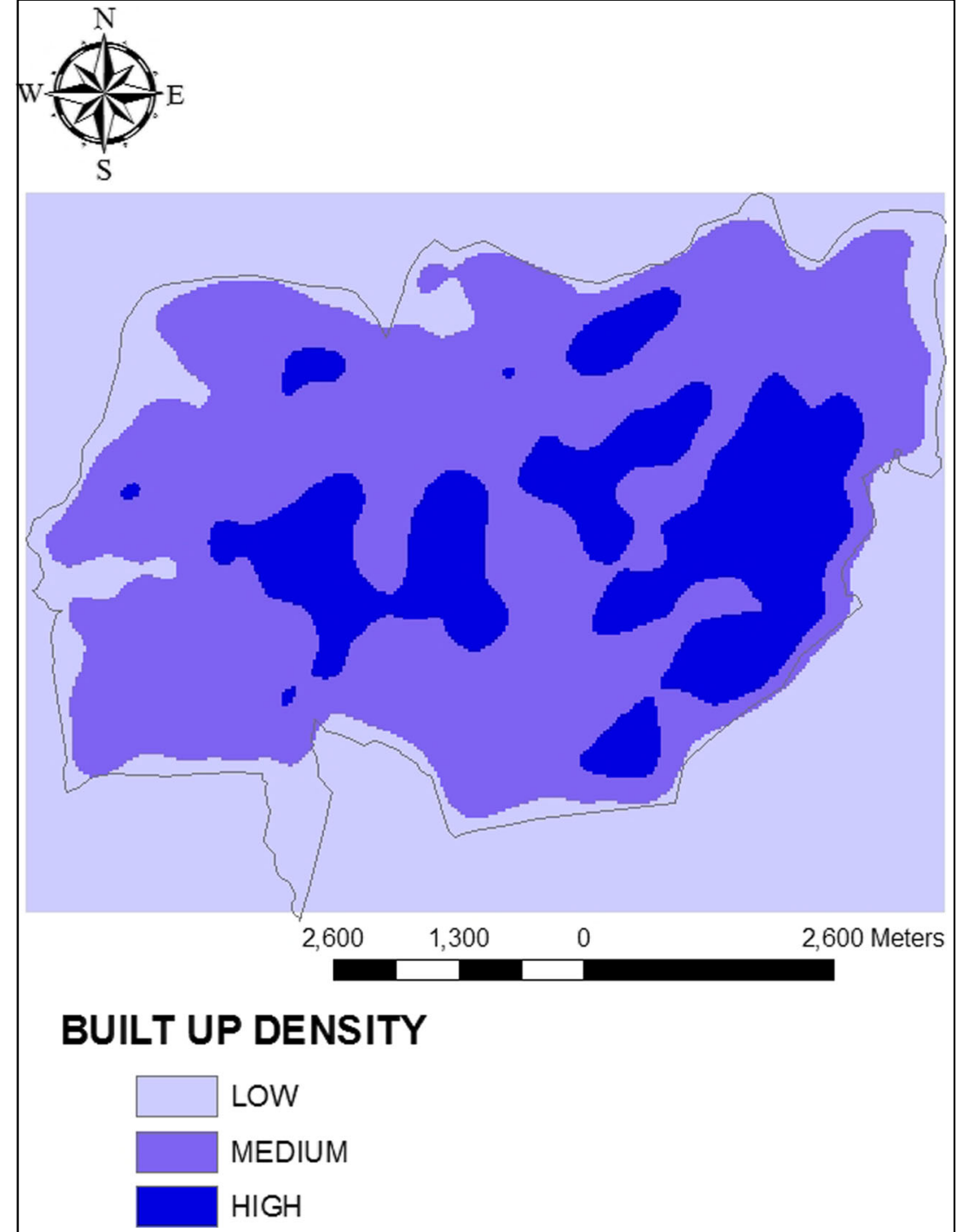

types have been changing from one type to another. As a result of this interaction of land uses, Mbarara Municipality has seen losses and gains in different land cover types over this period. Mbarara Municipality built-up area grew by $107 \%$ between 1984 and 1999 and $37 \%$ between 1999 and 2014. The overall percentage growth of the built-up area of Mbarara Municipality from 1984 to 2014 was $187 \%$. It can therefore be concluded that these losses and gains are greatly attributed to Mbarara Municipality's built-up area over this 30-year period. Results showed that the built-up area in Mbarara Municipality has expanded significantly since 1984 and this has come at the expense of all other cover types in Mbarara Municipality which over time lost a total of 1600.65 ha of cover area between 1984 and 2014 (Table 5).

However, this has not been the only factor behind land cover change in Mbarara Municipality. The continued interaction of land uses with each other was another contributing factor to land conversion. Increased population over the years and associated human activities also led to significant landscape alterations where forests, wetlands, grasslands, and other wilderness areas came to be replaced with farms, pastures, factories, stores, businesses, roads, and streets (Cowden et al. 2006). The gradual rise in population between 1984 and 1999 (Table 6) saw a significant rise in the built-up area of Mbarara Municipality. This corresponding rise in built-up area was as a result of the need for settlement and an increase in commercial activities.

One of the most effective methods used in monitoring land cover changes is remote sensing. The accuracy of this method in studying land cover changes in Mbarara Municipality was determined by the kappa coefficient where a score ranging from 0.7 to 0.83 was considered a reliable representation of what is on ground (Congalton and Green 1999).

Spatial and statistical analysis tools namely Moran's I statistic and nearest average neighbor were influential in examining the nature of built-up features for the years 1984, 1999, 
Fig. 11 Leapfrog sprawl

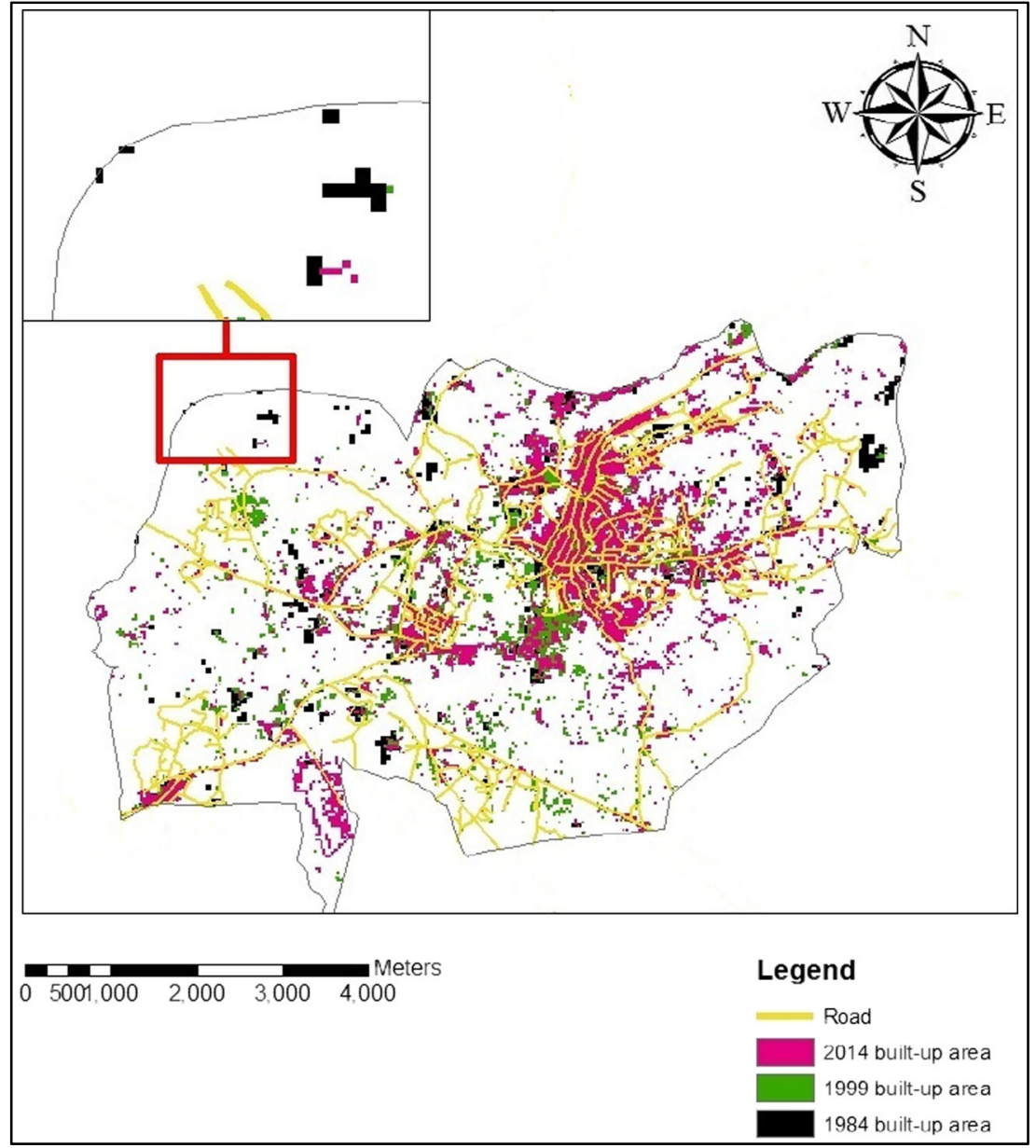

and 2014 and thus determining the direction and types of sprawl experienced in Mbarara Municipality.

The trend of growth of built-up area of Mbarara Municipality from 1984 to 2014 is similar to the that experienced by Bhubaneswar city which is one of the fast growing cities in India, whose growth in built-up area between 1998 and 2005 affected many forms of land cover such as agricultural area, vegetation, and vacant or bare land in the periphery (Naik et al. 2013). A polynomial type of growth as experienced by both urban centers explains uneven growth rates in built-up areas for different years. A fall in growth rate between 1999 and 2014 for Mbarara Municipality meant a fall in built-up density, a characteristic of urban sprawl given by Rowley (2001). To assess this, the OECD sprawl index was found most appropriate to measure the rate at which Mbarara Municipality was sprawling give the availability of data on both population and built-up density for the years 1984, 1999, and 2014.

With a growth in population by just 31,515 people from 1984 and a growth in built-up area by about $2.7 \mathrm{~km}^{2}$, Mbarara Municipality was experiencing sprawl in 1999 as the rate at which the built-up area was growing was greater than that of population; thus, the density of the urban area was low. A score of $7.6 \%$ on the OECD sprawl index means that
Mbarara Municipality ranked almost the same as cities found in Estonia and Portugal which scored 9.1 and $6.5 \%$, respectively (OECD 2013). Urban sprawl has been known to be a severe problem in both these countries for a long time (Couch et al. 2007).

The sprawl index score of $-7 \%$ between 1999 and 2014 is explained by the fact that the municipality saw an increase in its population by $47.5 \%$ contrary to the size of built-up area that grew by just $3.86 \%$. This means that during this period, the municipality was not experiencing urban sprawl. According to OECD 2013, countries whose average cities' sprawl index score is closest to $-7 \%$ are UK whose score was $-4.4 \%$ and Norway which scored $-8.5 \%$. The nature of urban sprawl in the cities of these countries is not so severe, for example, among the cities in Europe, Norway's cities are among the leading examples of concentrated and compact urban development (Næss and Strand 2012). Thus, a score towards $-8.5 \%$ is a great indicator that Mbarara Municipality had to a greater extent overcome the urban sprawl issue between 1999 and 2014.

However, an overall urban sprawl index score of $-4.3 \%$ does not necessarily mean that Mbarara Municipality has completely become free of sprawl since 1984 as the nature 
Fig. 12 Cluster sprawl

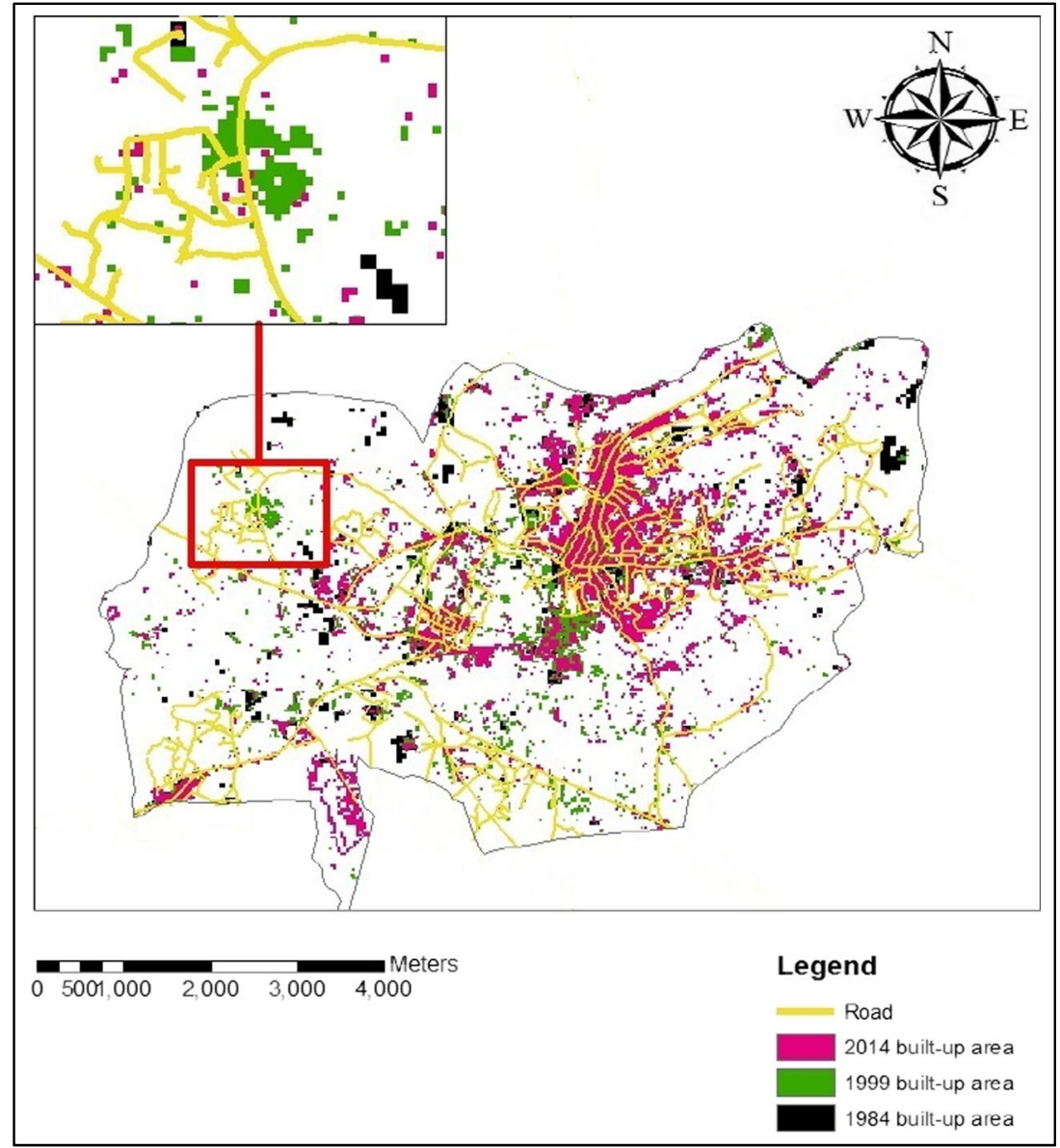

of sprawl in Mbarara Municipality during this period can closely be related to some cities in countries such as Belgium that scored an average of $-4.3 \%$ but still experiencing urban sprawl. However, much improved planning policies were introduced in Belgium through passing laws and introducing counter sprawl developments that had characterized preceding years (Decker 2011), sprawl is still evident in Belgian cities like Flanders. More still, cities in Switzerland which scored an average of $-4.2 \%$ are losing a total land area equivalent to 12 football pitches to sprawl everyday according to Pauchard (2012). More so, an average per capita land consumption of 0.01 ha equivalent to two football pitches is a good indicator of how much land was consumed by urban sprawl in Mbarara Municipality between 1984 and 2014.

The OECD sprawl index was therefore able to give an insight into how much land Mbarara Municipality has been losing to sprawl since 1984 but may not conclusively explain this using the index score.

According to Wilson and Chakraborty (2013), one of the most common approaches to defining sprawl is to focus on its physical characteristics as a particular pattern of development. As revealed in Fig. 7, most of the built-up area in Mbarara Municipality is in Kakoba division as this has been the direction growth patterns since 1984. The continued expansion of the built-up area in Kakoba division has largely influenced fragmentation of built-up density and uneven growth in other divisions most especially Nyamitanga. As a result, development further away from Kakoba has been characterized by low densities and increased distance from the main CBA (Fig. 9) as well as dispersion all of which are incentives to continued sprawling in Mbarara Municipality. This dispersion and fragmentation has encouraged an exponential trend of growth of the built-up area in Mbarara Municipality. An $R$ squared value of 0.35 means that the size of built-up area to some extent tends to decrease as the distance from the main CBA. This is a good indicator of the relationship between the size of the built-up area and the distance from the center given that a study done by MacDonald and Prather (1994) on suburban employment centers in Chicago obtained $R$ squared values ranging from 0.258 to 0.336 to relate employment density to the distance to the CBD.

The nature of urban sprawl in Mbarara Municipality is majorly in three forms, strip, leapfrog, and cluster. Spatial statistics clearly reveal the extent of low densities of built-up areas and dispersion and therefore classifying Mbarara Municipality as generally experiencing cluster sprawl as explained by its Maron's 1 score of 0.91 . The average nearest neighbor ratio score of 1.65 also indicates leapfrog development. 
Strip development in Mbarara Municipality has gradually developed since 1984 and is attributed to the need to extend services to areas further away from the CBA and as a result, land along roads tends to avail opportunities for commercial activities. This explains the existence of this type of sprawl in Mbarara Municipality.

\section{Conclusions}

The continued trend of land cover change and conversion in Mbarara Municipality is largely attributed to the growth in the size of the built-up area by $187 \%$ between 1984 and 2014 . Land cover changes were quantified with the use of statistics obtained from land cover maps generated through remote sensing.

Although remote sensing was largely successful in detecting and studying land cover changes in Mbarara Municipality between 1984 and 2014, it cannot be heavily relied on as different images from different time periods possess different characteristics and this makes it harder for image interpretation and easier for errors to occur.

The use of geographical information systems was also very essential in its role towards visualizing, quantifying, and classifying sprawl in Mbarara Municipality as strip, leapfrog, and cluster development.

\section{Recommendations}

Land cover conversions brought about by the rise in population and growth of commercial activities in the municipality should be checked by taking zoning practices seriously by planning authorities in Mbarara Municipality to regulate land use practices so as to check illegal land conversions. Although the structural plan of Mbarara Municipality 2007-2017 sets aside areas for different land uses, for example, residential, commercial, recreational, and agricultural areas, it has not stopped land conversions as built-up areas keep coming up in areas set aside for different uses.

Creation of self-sufficient local communities with adequate densities so as to ensure more efficient use of urban spaces is necessary. This can be done through advocating for high density of built-up areas with a variety of land uses. This is essential in combatting low-density urban sprawl as it also helps increase the size of the commercial areas of CBAs. Highdensity developments can also be promoted through "high rise" and "urban fill" to reduce the geographical expansion of the municipality and encourage compactness. This should be done especially in the fringe areas and in parts such as Kamukuzi with low density. High per capita land consumption in Mbarara Municipality which was at 0.01 ha by 2014 is one of the major reasons for urban sprawl. This is as a result of high cost of land in already built residential areas or congestion that leads to the movement of people away from CBAs. High per capita land consumption can however be overcome by encouraging settlement in affected areas which can be done through the extension of social services such as water and electricity as well as roads. This would increase settlement and in turn reduce per capita land consumption in these areas.

One of the most common types of sprawl in Mbarara Municipality is strip development. Therefore, the road network in Mbarara Municipality must be used in the best suitable way to discourage any form of sprawl as it can encourage compact growth of densities in low-density areas. The concentration of the road network in a designated area of growth limits the unplanned expansion tendencies that the municipality might take.

More still, Mbarara Municipality still has the potential to expand into parts of Nyamitanga and Kamukuzi that are largely characterized by low built-up densities. The re-direction of growth towards these areas would be a great effort in the fight against urban sprawl in Mbarara Municipality.

Acknowledgments Lots of thanks go to Paul I. Mukwaya and Daniel Waiswa for their attention and guidance. All their efforts to make the study successful will always be remembered.

Open Access This article is distributed under the terms of the Creative Commons Attribution 4.0 International License (http:// creativecommons.org/licenses/by/4.0/), which permits unrestricted use, distribution, and reproduction in any medium, provided you give appropriate credit to the original author(s) and the source, provide a link to the Creative Commons license, and indicate if changes were made.

\section{References}

Baboo SS, Devi MR (2010) Integrations of remote sensing and GIS to land use and land cover change detection of Coimbatore district. Int J Comput Sci Eng 2:3085-3088

Beck R, Kolankiewicz L, Steve AC (2003) Outsmarting smart growth: population growth, immigration, and the problem of sprawl. Center for Immigration Studies, Washington, DC

Beesley, K. B. (1993) The rural-urban fringe: a bibliography. Occasional papers (15). Trent University

Brezzi M, Veneri P (2014). Assessing polycentric urban systems in the OECD: country, regional and metropolitan perspectives

Bruegmann R (2005). A compact history. The University of Chicago Press

Burchfield M, Overman HG, Puga D, Turner MA (2006) Causes of sprawl: a portrait from space. Q J Econ 121(2):587-633

Campbell JB (2007) Introduction to remote sensing, 4th edn. The Guilford Press, New York

Congalton RG, Green K (1999) Assessing the accuracy of remotely sensed data: principles and practices. Lewis Publications, Boca Raton

Couch, C., Leontidou, L., \& Petschel-Held, G. (2007). Urban sprawl in Europe: Landscapes, land-use change \& policy. Oxford: Blackwell

Cowden JR., Watkins D and Croley IITE (2006). Investigating urban land use effects on runoff by using the distributed large basin runoff model 
Decker DP (2011) Understanding housing sprawl: the case of Flanders, Belgium. Environ Plan A 43(7):1634-1654

Ewing RH, Pendall R, Chen DDT (2002) Measuring sprawl and its impact. Smart Growth America, Washington, D.C.

Frequently asked questions about landsat missions. (2013). Retrieved from http://landsat.usgs.gov/L8 band_combos.php

Fulton WB, Reason Public Policy Institute. \& Solimar Research Group (2001) Smart growth in action: housing capacity and development in Ventura County. Reason Public Policy Institute, Solimar Research Group, Reason Foundation, Los Angeles

Galster G, Hanson R, Ratcliffe M, Wolman H, Coleman S, Freihage J (2001) Wrestling sprawl to the ground: defining and measuring an elusive concept. House Policy Debate 12:681-717

Kabenge M and Mfutumkiza D (2013) Impact of settlements and agriculture on wetland cover patterns in Mbarara Municipality. Proceedings of the second Uganda Conservation Conference, Vol. 1 Kampala, Uganda. ISBN 997071401.0

Kaplan DH, Wheeler JO, Holloway SR, Hodler TW (2004) Urban geography. Wiley, Hoboken

Knaap G, Song Y, Nedović-Budić Z, Lincoln Institute of Land Policy (2005) Measuring patterns of urban development: new intelligence for the war on sprawl. Lincoln Institute of Land Policy, Cambridge

MacDonald JF, Prather PJ (1994) Suburban employment centres: the case of Chicago. Urban Studies

Moran PAP (1948) The interpretation of statistical maps. J R Stat Soc 10(2):243-251

Muneza S (2014). Push for Mbarara City: Mwesigye Halts Proposal to Annex Several Sub counties, Redpepper. Retrieved from http://www.redpepper.co.ug/push-for-mbarara-city-mwesigyehalts-proposal-to-annex-several-sub-counties/

Murayama Y (2011) Zonal analysis: a GIS lecture tutorial. Retrieved from http://giswin.geo.tsukuba.ac.jp/sis/tutorial/Zonal_Analysis_ RCEstoque_2011.pdf Zonal Analysis

Naik, Milan (2013). Urban sprawl of Bhubaneswar city using GIS applications and entropy. Thesis/Dissertation ETD. http://ethesis.nitrkl. ac.in/5024/1/109CE0053.pdf
OECD (2013), OECD Regions at a Glance 2013, OECD Publishing, Paris. doi:10.1787/reg_glance-2013-en

Ojima R and Hogan DJ (2008) Mobility, urban sprawl and environmental risks in Brazilian urban agglomerations. Challenges for the urban sustainability in a developing country

O’Sullivan D, Unwin D (2003) Geographic information analysis. Wiley, Hoboken

Paolini L, Grings F, Sobrino J, Jimenez M, Karszenbaum H (2006) Radiometric correction effects in Landsat multi-date/multi-sensor change detection studies. Int J Remote Sens 27(4):685-704

Pathan SK, Shukla VK, Patel RG, Patel BR and Mehta KS (1991) Urban landuse mapping: a case study of Ahamedabad city and its environs. Ind Soc Remote Sensing

Pauchard O (2012) Swiss seek to limit urban sprawl. Retrieved from http://www.swissinfo.ch/eng/swiss-seek-to-limit-urbansprawl $/ 32339240$

Peter Næss TN, Strand A (2012) Oslo's farewell to urban sprawl. Eur Plan Stud. doi:10.1080/09654313.2011.530395

Rowley TD (2001) Development by design: land use planning and regulation in rural communities. University of Kentucky: Department of Agricultural Economics, Lexington

Shermeyer J, Haack B (2015) Remote sensing change detection methods to track deforestation and growth in threatened rainforests in Madre de Dios, Peru. J Appl Remote Sens 9(1):96040

Ssengendo W (2013) Mbarara eyes city status, The New Vision

UNICEF (2012) The state of the world's children 2012: children in an urban world. UNICEF, New York

United Nations Human Settlements Programme. (2012). State of the world's cities, 2012/2013: Prosperity of cities. Nairobi, Kenya: United Nations Human Settlements Programme (UN-HABITAT)

Wilson B and Arnab Chakraborty (2013) The environmental impacts of sprawl: emergent themes from the past decade of planning research. Multidisciplinary Digital Publishing Institute

Zhou Q (2015) Comparative study of approaches to delineating built-up areas using road network data. Trans GIS. doi:10.1111/tgis.12135 